\title{
Landscape Complexity Effects on Fisheries: Insights from Marine Landscape Ecology
}

\author{
Corey $\operatorname{Garza}^{1}$
}

Published online: 6 June 2016

(C) Springer International Publishing AG 2016

\begin{abstract}
Fisheries management has typically focused on the use of mathematical modeling to estimate current and future population trends to maintain the maximum sustainable yield in managed populations. However, modern advances in geospatial technologies and the emerging field of marine landscape ecology now provide landscape approaches and theory that can be applied in the management of marine fisheries. The use of landscape ecological approaches can provide important insights into the role that landscape complexity plays in the population dynamics and habitat requirements of commercially important species. Here, I review recent advancements in geospatial technologies and marine landscape ecology and their application to one experimental marine landscape study, and three studies dealing with managed fisheries populations across complex marine landscapes. I close with a discussion of emerging approaches in marine geospatial technology and how they may further enhance our understanding of the relationship of landscape complexity to the ecological dynamics of managed marine populations.
\end{abstract}

Keywords Marine landscape ecology $\cdot$ Landscape complexity · Spatial analysis · Geospatial technologies · Fisheries

This article is part of the Topical Collection on Interaction of Landscape Structure and Natural Resource Management

Corey Garza

cogarza@csumb.edu

1 School of Natural Sciences, California State University, Monterey Bay 100 Campus Center, Seaside, CA 93933, USA

\section{Introduction}

Historically, fisheries management has focused on maximizing catch while at the same time attempting to maintain population stability in commercially important species $[1,2]$. To date, many of the tools used in fisheries management have employed mathematical modeling approaches to estimate future population trends in managed species. The most notable of these, the Ricker Stock Recruitment model, has been used globally to estimate future catch totals and the maximum sustainable yield in a variety of fisheries. Coupled with this approach have been regional policies of seasonal fishing activity and size and catch limits [1]. Yet, despite these management approaches, global fisheries have witnessed ongoing declines which suggest that additional ecological considerations need to be incorporated into managing commercially important fishery species [3].

Within the last 20 years, the fisheries management community began moving towards incorporating considerations of habitat type into management practices that had historically focused on estimating the maximum sustainable yield for populations. The most notable of these efforts is seen in the use of Marine Protected Areas (MPAs). Their original designs were framed around protecting economically important species and specific habitat types with less consideration for the ecological value of habitat complexity or the importance of ecological processes that occurred within an MPA [4-6]. These initial limitations aside, many early MPAs around the world demonstrated positive effects on targeted populations, such as increases in abundance and body size. Positive effects of MPAs on commercial species have been reported from regions as diverse as New Zealand [7, 8], Chile [9, 10], Australia [11] and British Columbia [12, 13]. In the United States, early MPAs saw success in areas such as the Florida Keys [14], portions of the mid-Atlantic region [15] and the Pacific 
Northwest $[16,17]$. In each of these cases, the presence of MPAs was cited as having a positive impact on populations of fishery species.

The ongoing development of the current global network of MPAs emphasizes consideration of the impact of reserve size on reserve functioning, connectivity among populations, and the inclusion of habitat critical to species across all their lifestages [18-20]. There has also been a scientific consensus that fisheries management needs to move towards ecosystembased approaches that can conserve multiple species, a strategy that entails the simultaneous conservation of multiple types of critical habitat [18-21]. This new approach to integrating key habitat features into the design of MPAs represents a clear advance in their design and implementation. However, current designs still suffer from the scale at which key habitat features that are used to designate MPAs are measured. This issue arises because MPAs are often designated based on single features that vary in scale from 10s to 100s of meters [22], scales outside of which many targeted species interact with their environment [23].

Features such as kelp forests or boulder fields may serve as a good first proxy for habitat types conducive to supporting targeted fisheries species. However, their sole use in MPA designation may mask other features such as geological and biological complexity (i.e., three-dimensional complexes of sessile invertebrates or algal turfs), which can help to further support populations of targeted species [24-26]. Thus, excluding multiple scales of habitat types in the design of MPAs can mask habitat components that can increase overall biological and geological complexity and associated ecosystem services (e.g., refuge and forage habitat). For example, the intertidal is one habitat that is often overlooked in the design of MPAs but contains many complex features (i.e., mussel beds, rocky crevices and algal turf communities) which are often excluded in the design process of current MPAs [27]. These particular features within the intertidal can add additional complexity to a system that can then be utilized as essential foraging, reproductive and shelter habitat [28-30]. Previous survey techniques and technologies (e.g., quadrats) may have made it logistically unfeasible to collect data at scales compatible with intertidal habitat designation, the majority of which are best classified at the sub-meter scale [27].

The field of landscape ecology has long examined the role that multi-scale landscape complexity plays in driving ecological process and patterns in nature [31]. Landscape ecological studies demonstrate how variation in landscape complexity can affect habitat configuration, the level of connectivity between populations [31,32], and the availability of resources [33]. In combination, variation in these landscape attributes can in turn affect local population dynamics. These ecological aspects of landscapes are key features of current metapopulation theory which has informed modern MPA design and implementation. Landscape complexity can also impart or enhance disturbance events in a community. For example, vertical layering in forests and mussels has been cited as playing a role in determining the relative impact of wind throw and wave-induced disturbance events in these communities [34]. Landscape complexity may also be a key feature in understanding the conservation and management of marine habitats, such as coral reefs [35], which can be highly susceptible to disturbance events.

Marine landscape ecology, sometimes labeled seascape ecology, looks to apply many of the theoretical underpinnings and scientific approaches of landscape ecology to studying the role of scale and landscape complexity (hereafter defined as three-dimensional complexes of biogenic and geological features) in the ecological dynamics of marine systems. It has only been within the last two decades that the scientific literature has seen an influx of papers which incorporate landscape theory into marine ecological studies, with some of the earliest studies applying these approaches to seagrass communities [36]. The earliest compendium of papers on the topic was first published in the journal Landscape Ecology [37] and featured studies that detailed both theoretical and applied uses of landscape ecology in the marine environment [37]. This was followed by a special issue in Marine Ecology Progress Series [38] that focused on the application of spatial approaches to the study of marine systems. The studies featured within each issue provided new theoretical and technical avenues through which the marine ecological sciences could incorporate considerations of landscape complexity into basic and applied research.

Coupled with new landscape-based perspectives in marine ecology, advances in digital photography, LIDAR, bathymetric mapping, and aerial drones have made it feasible to rapidly collect data from marine systems across multiple levels of ecosystem complexity [39]. Improvements in geographic information systems (GIS), computing and spatial statistics now make it possible to visualize and analyze complex habitat data in ways that were not previously possible. These advances have supported studies that have revealed how landscape complexity in marine environments drives ecological interactions in a number of systems. This type of basic research can in turn be used to provide fisheries managers with insight into the importance of incorporating landscape complexity into the design of modern fisheries management plans. Here, I discuss how technological and analytical approaches from this emerging field can support fisheries management strategies that look to incorporate landscape complexity into their designs.

\section{Geospatial Technologies: Advances and Opportunities}

Beginning in the mid-1990s, advances in computing improved the way that ecologists were able to visualize and analyze data. 
This improvement was especially significant for the field of landscape ecology, as improved computer graphics allowed for clearer visualizations of ecosystems via the emergence of GIS as a primary spatial analysis tool for examining complex ecosystem data [40, 41]. Coupled with improvements in computer graphics and the ability to better visualize data, was the ability to more effectively apply spatial statistics to the analysis of complex spatial data. The rise of $\mathrm{R}$ statistical software as a free alternative for analyzing spatial data has further helped the inclusion of spatial statistics in modern ecological analysis. These advances in computing technology helped support the advancement of landscape-based ecological theory in marine systems that had started to take shape in the early 2000s [42, 43]. In particular, improvements in remote sensing approaches, such as LIDAR and aerial photography, allowed for rapid data collection over broad swaths of an ecosystem and enabled rigorous testing and subsequent analysis of landscape ecological theory that was not previously possible. Such applications provided new insights on how landscape complexity in marine systems drives patterns of species distribution and abundance [44].

Advances in computer programming, robotics and artificial intelligence led to the development of remotely operated vehicles (ROVs) [45] and autonomous underwater vehicles (AUVs) [46] which provide platforms through which scientists can now explore broad swaths of marine environments that could only be briefly explored through SCUBA. Concordant improvements in bathymetric mapping, with a move from single beam to multi-beam and sidescan sonar, drastically improved the ability to resolve fine-scale features on the seafloor $[35,47]$. When coupled with the use of AUVs and ROVs, bathymetric mapping helped to detail wide swaths of the ocean floor that were previously undescribed. This enabled studies in subtidal environments that were able to discern the role that landscape complexity played in mediating the relationship between subtidal biological communities and their surrounding physical environment. These studies have helped to disentangle the complexity of interactions that occur in the subtidal, and have provided crucial ecological information to help improve management of fisheries resources in coastal systems [35, 47]. As computing and engineering approaches continue to improve, geospatial technologies have the potential to play an even larger role, not only in basic ecological research but also in providing key insights into how habitat complexity can be integrated into modern fisheries management.

\section{Recent Marine Landscape Ecological Studies: Examples From Experimental and Fisheries Studies}

\section{Rocky Intertidal Communities}

One of the earliest investigations into the role of landscape complexity in the marine environment comes from the rocky intertidal and focused on a field test of one of the first landscape-based cellular automata models for marine systems [39, 42, 48]. Robles et al. [39] examined the hypothesis that positive interactions among conspecifics within a population could produce landscape patterns in boundary intensity. This represented a shift from traditional ecological paradigms of boundaries being driven by strong interspecific interactions $[49,50]$. In turn, they also proposed that the sharpness of species boundaries could be driven, in part, by the complexity of the underlying landscape and its interaction with the surrounding environment.

In their study, spatial variation in boundary distribution and sharpness emerged because individuals would aggregate in the face of a potential limiting factor (e.g., wave stress) [39]. They further examined how spatially varying these neighborhood processes across a spatial gradient of tidal immersion and wave energy affected boundary sharpness and location in mussel beds [39, 48]. Running their model with and without neighborhood processes demonstrated that the neighborhood processes increase boundary intensity above that caused by environmental gradients alone, and consequently abrupt (high-intensity) boundaries emerged as a function of spatial variation in landscape complexity [48]. Trends generated by their model were compared with photo-mosaics of intertidal mussel beds, Mytilus californianus, on rocky shores of British Columbia. Their analysis involved GIS interpolation of boundary locations and estimation of the corresponding boundary intensities using a contagion index [39]. The similarity between predicted and real trends in boundary intensity (sharp vs. diffuse) over a wave energy gradient (Fig. 1) suggested that spatially varying neighborhood processes determines much of the landscape-scale variation in boundary intensity. Discrepancies from predicted trends suggested that increasing landscape complexity disrupted neighborhood interactions resulting in increasing diffusivity in population boundaries.

\section{Temperate Reefs}

This demonstration that complexity in rocky marine landscapes can drive patterns of species distribution and abundance advanced our basic understanding of the ecology of the marine environment. While not focused on fisheries, the work of Robles et al. [39] also helped lead to applications of this knowledge to applied uses in the marine environment. For example, Young et al. [47] tested the applicability of terrestrial landscape modeling techniques for predicting the distribution of three ecologically and economically important rockfish species at Cordell Bank National Marine Sanctuary. Young et al. [47] used auto-classified multi-beam bathymetry along with georeferenced submersible video transect data of the seafloor and demersal fishes to model the abundance and distribution of rockfish. Generalized linear models, which controlled for 
Fig. 1 Photo mosaic of rocky intertidal mussel bed depicting the distribution and intensity of mussel bed boundaries as a function of tidal height and wave velocity. Cell color in the grids indicates state: orange $=$ unoccupied, increasing variation in remaining hues of color represent increasing variation in mussel bed boundary fragmentation. The color bar indicates alongshore gradient in wave energy, represented by a raster interpolation of maximum flow speeds measured by wave dynamometers. The vertical dimension of the flow speed interpolation has been compressed to $1 / 4$ th its original span. Mussel tear-outs generated earlier by winter storms are outlined in yellow. The image is referenced relative to mean lower low water [38]

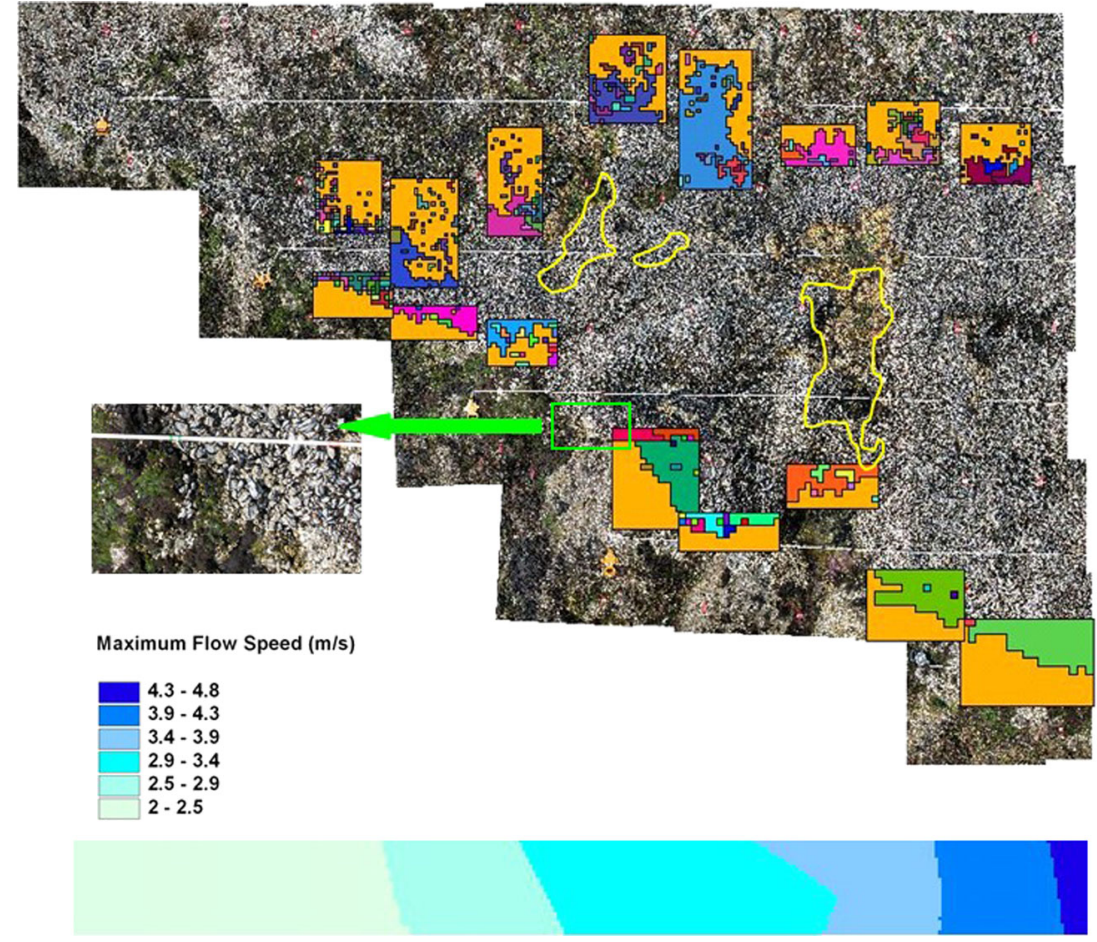

spatial autocorrelation, were created using habitat classification analyses of high-resolution digital elevation models combined with fish presence/absence observations [47].

Their models incorporated numerous aspects of seafloor complexity that included slope, rugosity and topographic position index (a measure of seamount height about the seafloor). The resulting GIS-based probability surface models generated for their study area proved reliable in predicting the distribution of all three of their study species (Fig. 2). The accuracies of their models for three species of rockfish, Sebastes rosaceus, S. flavidus and S. elongatus, were 96, 92 and $92 \%$, respectively. The probability of the occurrence of $S$. flavidus and S. rosaceus was highest in the high-relief rocky areas and lowest in the low-relief, soft sediment areas [47]. The model for S. elongatus had an opposite pattern, with the highest predicted probability of occurrence taking place in the low-relief, soft sediment areas and a lower probability of occurrence in the rocky areas. Here, we have an early application of landscape-based GIS models that demonstrate how variation in landscape complexity and composition drives the distribution of commercially important fishery species. These results indicate that site-specific and species-specific algorithmic habitat classifications applied to high-resolution bathymetry data could accurately extrapolate the results from in situ video surveys of demersal fishes across broad areas of complex underwater habitat [47]. Their results also suggest that geological features and variation in landscape complexity were supporting different prey resources for each of their study species, thus enabling fine-scale habitat partitioning between these three species [47]. These results can feed into broader management needs for accurate and efficient estimation of actual and potential species distribution as a critical component for effective ecosystem-based management and MPA design.

\section{Sandy Bottom Habitat}

High-resolution mapping has also been used to inform the management of one of the largest and most profitable fisheries in the world, the California market squid, Dorthyteuthis opalescens [51] which is concentrated largely on nearshore squid spawning aggregations. Because of its economic importance, a central concern for sustainable squid fisheries in California is to determine if reproductive activities and egg laying occur at rates that can support harvestable populations of this sub-annual species. Using high-resolution data collected via acoustic mapping methodology, Young et al. [51] estimated a $99 \%$ decrease in egg mops abundance from 2005 to 2007. Sidescan sonar images suggested that, although squid prefer a sandy substrate as their primary egg mop habitat, the depths across which mops occurred and their spatial distribution differed significantly between surveys. This variation appeared to be due in part to the interaction between oceanographic currents and the underlying landscape complexity, which in turn determines the amount of, and where, sandy flat habitat that squid use to spawn appear on a year to year basis 
Fig. 2 GIS probability map of yellowtail rockfish, Sebastes flavidus, distribution along Cordell Bank off the coast of Central California. Red colors high probability of rockfish occurrence, while blue cells represent low probability of occurrence. Grid reference system in WGS 1984, UTM zone $10 \mathrm{~N}$ [46]

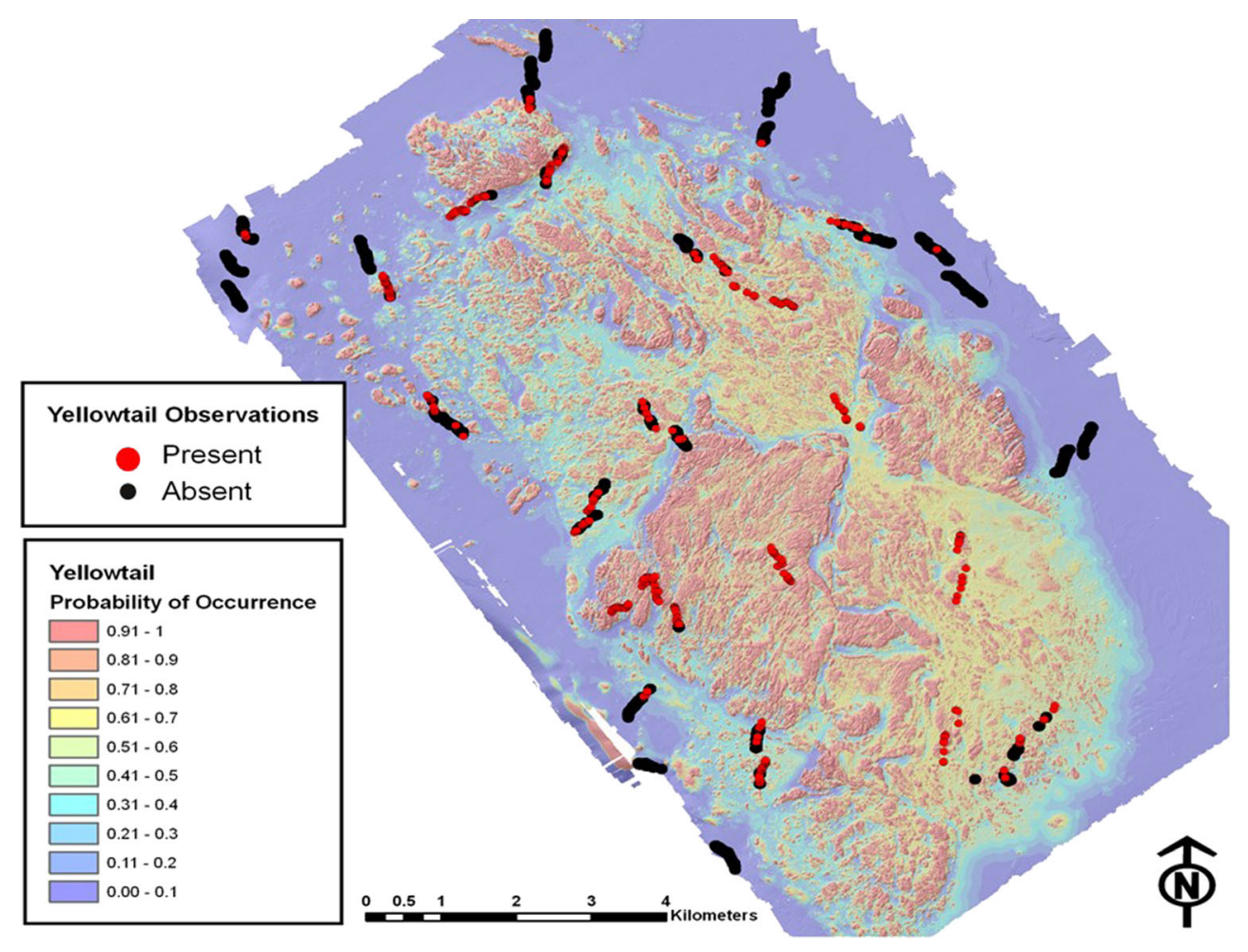

[51]. Thus, this yearly variation in the spatial positioning and abundance of their primary spawning habitat could be used to explain the observed decrease in egg mop abundance [51].

These results demonstrate that sidescan sonar surveys can serve as an important tool to aid management of the California market squid fishery through the monitoring, designation and adaptive management of seasonally variable no-take spawning zones. More broadly, their work provides an early example of how seasonal variation in landscape complexity and composition may be used to inform adaptive management of commercially important fishery species.

\section{Coral Reefs}

Marine landscape ecological approaches are also being used beyond the West Coast of North America to inform fisheries management. For example, Pittman et al. [35] provide one example of how remote sensing data and multi-scale statistical modeling can determine the influence of landscape complexity on connectivity and distribution in coral reef fish species. Coral systems are ideal for investigating the relationship of landscape complexity to managed species, as reef systems exist as a network of interconnected patches the level of connectivity of which can be affected by the underlying complexity of the subtidal landscape that connects them [35]. Given their high level of connectivity and movement of individuals between patches, reefs can also be thought of as operating under any number of metapopulation models that are traditionally examined in terrestrial systems [51]. Coral reefs can also harbor economically important species which can be some of the most susceptible to anthropogenic impacts and large external forcing factors such as those imposed by hurricanes [35].

In their study, Pittman et al. [35] use maximum entropy species distribution modeling to achieve a $92 \%$ accuracy rate in predicting the distribution of fish species across a Caribbean coral reef. More specifically, they demonstrated that the location on the coral reef shelf coupled with the topographic complexity of the reef landscape could reliably predict the distribution of fish species across a coral reef. Of particular note in their study is that landscape predictors differed among species, yet rarely changed across spatial scales ranging from 10 s to 100 s of meters. This suggests that single landscape-derived variables can be used in the development of management plans across multiple scales of ecosystem organization and management [35]. Their work lends itself to an evergrowing body of literature that demonstrates how geospatial visualization and analytical approaches can enhance our understanding of the role that landscape complexity can play in fisheries management. Furthermore, their approaches demonstrate a cost-effective approach to support conservation prioritization in MPA design, zoning in marine spatial planning, and ecosystem-based fisheries management.

\section{Future Directions}

Recent applications of geospatial technologies to marine ecological studies have provided new insights into how 
landscape complexity can affect population dynamics in coastal systems, especially as it pertains to supporting management of commercially important species in coastal ecosystems. Recent advances in technologies such as aerial unmanned vehicles, aka drones, and the ability to incorporate stable isotope data into GIS platforms can enhance the ability to understand multi-scale relationships between ecological patterns and landscape complexity in marine systems. Furthermore, these new advances can improve our understanding of how trophic relationships in managed marine populations vary as a function of landscape complexity in the marine environment.

Drones have increased in their popularity in recent years owing to their ability to rapidly capture multiscale data on landscape complexity at a relatively low cost $[52,53 \cdot \bullet]$. Ecologists and fisheries managers have traditionally relied on remotely sensed satellite data or LIDAR flights which are costly and, though they may capture large swaths of data, can capture data at spatial resolutions that preclude investigations of how managed populations interact with their environment at finer spatial scales $[23,53 \bullet \bullet]$. This can in turn preclude rigorous quantitative assessments on how landscape complexity drives the ecological dynamics of managed marine populations. Modern drones can bridge this gap, and provide a low-cost alternative for capturing multi-scale data on landscape complexity and composition in the nearshore marine environment at sub-meter scales (Fig. 3a, b). Drones come with a number of advantages that can help in enhancing fishery management plans. These include but are not limited to (1) carrying various imaging or non-imaging payloads to collect spatial datasets, (2) increased flexibility in survey intervals, (3) low-altitude flight allows sensors to collect finer spatial resolution data, and (4) operating costs are low [53••].

Coupled with recent improvements in mapping technologies is the ability to incorporate stable isotope data into GIS databases (isoscapes). Compared to more traditional diet research methods such as gut content analysis, stable isotope analysis (SIA) supports a more temporally integrated estimate of important prey [54]. SIA-based trophic studies rely on the assumption that consumers incorporate the isotopic signature of their prey into their tissues in a predictable manner, creating a long-term record of their main prey sources [55]. Stable isotope analyses are low cost and can be contracted out to stable isotope facilities at a cost of US11.00 to $\sim 12.00$ dollars a sample. Investigators simply need to prepare their samples in the manner provided by a contract laboratory, thereby avoiding having to invest financial resources in procuring and operating stable isotope analytical equipment.

Historically used to assess connectivity and trophic positioning in terrestrial populations, SIA is now being used to

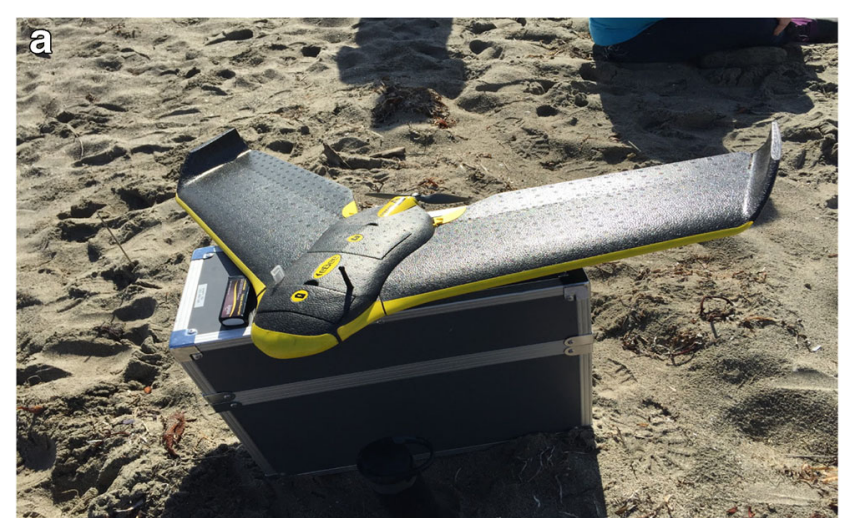

\section{b}

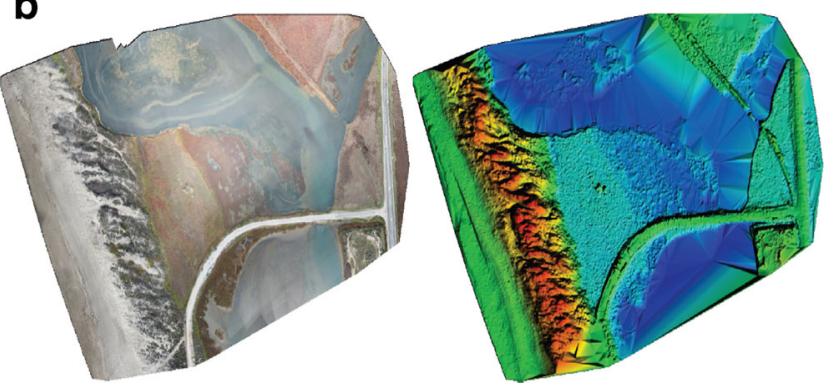

Fig. 3 a E-bee aerial unmanned vehicle prior to deployment at Elkhorn Slough, Californa. b Photo mosaic (left) and $2.5-\mathrm{cm}$ digital elevation model (right) of Elkhorn Slough captured using E-Bee. (Images courtesy of R. Kvitek and P. Iampietro)

assess connectivity among large oceanic species that are often the focus of many fisheries agencies [56, 57]. Isoscapes can allow fisheries managers to visualize how complex marine landscapes affect population connectivity, and to quantify the probability that a given landscape will affect connectivity between or the trophic positioning of managed species [58, $59 \cdot, 60^{\bullet}$. Examples of this type of approach can be seen in fisheries-related species such as tuna [56] and marine mammals [61]. Recent applications have also been applied to nearshore benthic fisheries such as the Pacific spiny lobster, Panuliurus interruptus [62] and reveal fine-scale coupling of lobster foraging preferences to sub-meter variation in landscape complexity and composition.

In the future, isoscapes may be able to provide a cost-effective method for answering population-level questions (i.e., stock discrimination) and provide a complementary approach to tagging technologies and genetic analysis $[53 \bullet \cdot]$. Recent data from the Southern California spiny lobster fishery [62] demonstrate that stable isotopes can discriminate between connected lobster populations on a scale of 10 s of meters, whereas traditional genetic approaches have typically distinguished unique populations on the scale of $1000 \mathrm{~s}$ of meters in the Southern California Bight [63]. With regards to cost, a single satellite tag can costs $\sim$ US $\$ 4000$, while satellite time costs $\sim$ US $\$ 8 /$ tag per day, which can represent a significant investment 
for the tracking of a single individual across a landscape. By contrast, for roughly US\$5000, the isotope values and subsequent connectivity of approximately 400 individuals can be determined [57]. Ultimately, an investigator's research objectives and budget should consider the added knowledge gained by the union of extrinsic and intrinsic tagging approaches in fisheriesbased studies. Isoscape approaches, when coupled with mapping and telemetry data in marine systems, can enhance the ability of natural resource managers to manage global fisheries via the ability to improve estimates of connectivity and foraging preferences in managed fisheries populations.

\section{Conclusions}

The field of marine landscape ecology offers new opportunities to advance our knowledge of spatial patterns and process in marine systems through theory that provides new insights into the role of landscape complexity in driving population structure. Emerging data acquisition and analytical techniques can improve quantitative inferences on how structural complexity affects patterns of species distribution and abundance. Beyond the advancement of basic knowledge, this advancement in the marine ecological sciences can also inform existing and future fisheries management approaches. Modern technological advances in GIS and spatial statistics provide clearer visualizations of ecosystem dynamics across complex marine landscapes, and the ability to make statistical inferences on these dynamics. Improvement in data acquisition techniques such as multi-beam sonar and LIDAR have improved the ability of coastal managers to resolve landscape features critical to fisheries management down to a scale of a few meters. Meanwhile, advances in drone and stable isotope approaches now provide low cost approaches for capturing landscape data and quantifying linkages between managed populations as a function of landscape complexity. The overall synthesis of these and future landscapebased approaches can offer new insights and approaches for managing and sustaining global fisheries.

Acknowledgments Thanks to R. Kvitek and P. Iampietro of the Seafloor Mapping Lab at California State University, Monterey Bay for providing the images used in Fig. 3.

\section{Compliance with Ethical Standards}

Conflict of Interest Dr. Garza has no conflicts of interests to declare.

Human and Animal Rights and Informed Consent This article contains no studies with human or animal subjects performed by the author.

\section{References}

Papers of particular interest, published recently, have been highlighted as:

- Of importance

-• Of major importance

1. Hilborn R, Branch TA, Ernst B, Magnusson A, Minte-Vera CV, Scheuerell MD, et al. State of the world's fisheries. Annu Rev Environ Resour. 2003;28:359-99.

2. Mangel M, Levin PS. Regime, phase and paradigm shifts: making community ecology the basic science for fisheries. Philos Trans R Soc Lond B. 2005;360:95-105.

3. Worm B, Hilborn R, Baum JK, Branch TA, Collie JS, Costello C, et al. Rebuilding global fisheries. Science. 2009;325:578-85.

4. Roberts CM. Selecting marine reserve locations: optimality versus opportunism. Bull Mar Sci. 2000;66(3):581-92.

5. Roberts CM, Branch G, Bustamante RH, Castilla JC, Dugan J, Halpern BS, et al. Application of ecological criteria in selecting marine reserves and developing reserve networks. Ecol App. 2003;13(1):S215-28.

6. Gladstone W, Davis J. Reduced survey intensity and its consequences for marine reserve selection. Biodivers Conserv. 2003;12: 1525-36.

7. Walls K. Leigh marine reserve, New Zealand. Parks. 1998;8:5-10.

8. Shears NT, Grace RV, Usmar NR, Kerr V, Babcock R. Long term trends in a partially protected vs. no-take marine park. Biol Conserv. 2006;132:222-31.

9. Castilla JC, Fernandez M. Small-scale benthic fisheries in Chile: on co-management and sustainable use of benthic invertebrates. Ecol Appl. 1998;8:S124-32.

10. Castilla JC. Roles of experiment and marine ecology in coastal management and conservation. J Exp Mar Bio Ecol. 2000;250(2000):3-21.

11. Graham NAJ, Evans RD, Russ GR. The effects of marine reserve protection on the trophic relationships of reef fishes on the Great Barrier Reef. Environ Conserv. 2003;30:200-8.

12. Wallace SS. Evaluating the effect of three forms of marine reserve on northern abalone populations in British Columbia, Canada. Conserv Biol. 1999;13(4):882-7.

13. Ardron JA, Lash J, Haggarty D. Modeling a network of marine protected areas for the central coast of BC. Version 3.1. Living Oceans Society, Sointula, British Columbia, Canada. 2002. Available from http://www.livingoceans.org/files/LOS MPA model v31web.pdf.

14. Bohnsack JA. Consensus development and the use of marine reserves in the Florida Keys, USA. Processing of the 8th International Coral Reef Symposium 2: 1922-1930. 1997.

15. Azimi S. Priority ocean area for protection in the mid-Atlantic: findings of NRDC'S marine habita workshop. New York: Natural Resources Defense Council; 2001.

16. Klinger T. Marine protected areas: examples from the San Juan Islands, Washington. Endanger Species Update. 2001;18:55-8.

17. Beck MW. The sea around us: marine regional planning. In: Groves $\mathrm{CR}$, editor. Drafting a conservation blueprint: a practitioner's guide to planning for biodiversity. Washingon, D.C: Island Press; 2003. p. 319-44.

18. Airame S, Dugan JE, Lafferty KD, Leslie H, McArdle DA, Warner RR. Applying ecological criteria to marine reserve design: a case study from the California Chanel Islands. Ecol Appl. 2003;13(1): S170-84.

19. Halpern BS. The impact of marine reserves: do reserves work and does size matter? Ecol Appl. 2003;13(1):S117-37. 
20. Gerber LR, Heppell SS. The use of demographic sensitivity analysis in marine species conservation planning. Biol Conserv. 2004;120(2004):121-8.

21. Leslie HM. A synthesis of marine conservation planning approaches. Conserv Biol. 2005;19(6):1701-13.

22. Guerry AD. Icarus and Daedalus: conceptual and tactical lessons for marine ecosystem based management. Front Ecol Environ. 2005;3(4):202-11.

23. Garza C. Relating spatial scale to patterns of polychaete species diversity in coastal estuaries of the western United States. Landsc Ecol. 2008;23:107-21.

24. Banks SA, Skilleter GA. Mapping intertidal habitats and an evaluation of their conservation status in Queensland. Aust Ocean Coast Manag. 2002;45:485-509.

25. Banks SA, Skilleter GA, Possingham HP. Intertidal habitat conservation: identifying conservation targets in the absence of detailed biological information. Aquatic Conserv Mar Freshwat Ecosyst. 2005; 15:271-88.

26. Hamilton SL, Caselle JE, Lantz CA, Egloff TL, Kondo E, Newsome SD, et al. Extensive geographic and ontogenetic variation characterizes the trophic ecology of a temperate reef fish on southern California (USA) rocky reefs. Mar Ecol Prog Ser. 2007;429:227-44.

27. Banks SA, Skilleter GA. The importance of incorporating fine-scale habitat data into the design of an intertidal marine reserve system. Biol Conserv. 2007;138:13-29.

28. Robles CD, Robb J. Varied carnivore effects and the prevalence of intertidal algal turfs. J Exp Mar Biol Ecol. 1993;166:65-91.

29. Robles CD, Alvarado MA, Desharnais RA. The shifting balance of littoral predator-prey interaction in regimes of hydrodynamic stress. Oecologia. 2001;128:142-52.

30. Smith JR, Ambrose RF, Fong P. Anthropogenic disturbance and the effectiveness of marine protected areas for protecting mussel bed communities along the California coast. Environ Manag. 2008;41: 599-612.

31. Ricketts TH. The matrix matters: effective isolation in fragmented landscapes. Am Nat. 2001;158:87-99.

32. Fahrig L. Effects of habitat fragmentation on biodiversity. Annu Rev Ecol Evol Syst. 2003;34:487-515.

33. Tewksbury JJ, Levey DJ, Haddad NM, Sargent S, Orrock J. Corridors affect plants, animals, and their interactions in fragmented landscapes. Proc Natl Acad Sci U S A. 2002;99: 12923-62.

34. Turner MG. Landscape ecology: what is the state of the science? Annu Rev Ecol Evol Syst. 2005;36:319-44.

35. Pittman SJ, Brown KA. Multi-scale approach for predicting fish species distributions across coral reef seascapes. PLoS ONE. 2011;6(5), e20583. doi:10.1371/journal.pone.0020583.

36. Irlandi EA, Ambrose Jr WG, Orlando BA. Landscape ecology and the marine environment: how spatial configuration of seagrass habitat influences growth and survival of the bay scallop. Oikos. 1995;72(3):307-13.

37. Hinchey EK, Nicholson MC, Zajac RN, Irlandi EA. Preface: marine and coastal applications in landscape ecology. Landsc Ecol. 2008;23:1-5.

38. Bostr m C, Pittman SJ, Simenstad C, Kneib RT. Seascape ecology of coastal biogenic habitats: advances, gaps and challenges. Mar Ecol Prog Ser. 2011;427:191-217.

39. Robles CD, Garza C, Desharnais RA, Donahue MJ. Landscape patterns in boundary intensity: a case study of mussel beds. Landsc Ecol. 2010;25(5):745-59.

40. Goodchild MF, Haining RP. GIS and spatial data analysis: converging perspectives. Pap Reg Sci. 2004;83:363-85.

41. Wright DJ, Heyman WD. Introduction to the special issue: marine and coastal GIS for geomorphology, habitat mapping and marine reserves. Mar Geod. 2008;31:1-8.
42. Robles CD, Desharnais RA. History and current development of a paradigm of predation in rocky intertidal communities. Ecology. 2002;83:1521-37.

43. Guichard F, Halpin PM, Allison GW, Lubchenco J, Menge BA. Mussel disturbance dynamics: signatures of oceanic forcing from local interactions. Am Nat. 2003;161:889-904.

44. Robles CD, Desharnais RA, Garza C, Donahue MJ, Martinez CA. Complex equilibria in the maintenance of boundaries: experiments with mussel beds. Ecology. 2009;90:985-95.

45. Cohan S. Trends in ROV development. Mar Technol Soc J. 2008;42(1):38-43.

46. Roberts GN, Sutton R (2006). Advances in unmanned marine vehicles (Vol. 69). IET. 433 pp.

47. Young MA, Iampietro PJ, Kvitek RG, Garza CD. Multivariate bathymetry-derived generalized linear model accurately predicts rockfish distribution on Cordell Bank, California. USA Mar Ecol Prog Ser. 2010;415:247-61.

48. Donahue MJ, Desharnais RA, Robles CD, Arriola P. Mussel bed boundaries as dynamic equilibria: thresholds, phase shifts, and alternative states. Am Nat. 2011;178(5):612-25.

49. Connell JH. Effects of competition, predation by Thais lapillus, and other factors on natural populations of the barnacle Balanus balanoides. Ecol Monogr. 1961;31(1):61-104.

50. Paine RT. Intertidal community structure. Oecologia. 1974;15(2): 93-120.

51. Young MA, Kvitek RG, Iampietro PJ, Garza CD, Maillet R, Hanlon RT. Seafloor mapping and landscape ecology analyses used to monitor variations in spawning site preference and benthic egg mop abundance for the California market squid (Doryteuthis opalescens). J Exp Mar Biol Ecol. 2011;407(2): 226-33.

52. Koh L, Wich S. Dawn of drone ecology: low-cost autonomous aerial vehicles for conservation. Trop Conserv Sci. 2012;5(2): 121-32.

53.• Anderson K, Gaston KJ. Lightweight unmanned aerial vehicles will revolutionize spatial ecology. Front Ecol Environ. 2013;11(3):13846. This insightful paper provides a comprehensive review of current and emerging applications of drones in spatial ecology.

54. Peterson BJ, Fry B. Stable isotopes in ecosystem studies. Annu Rev Ecol Syst. 1987;18:293-320.

55. Post DM. Using stable isotopes to estimate trophic position: models, methods, and assumptions. Ecology. 2002;83:703-18.

56. Graham BS, Koch PL, Newsome SD, McMahon KW, Aurioles D. Using isoscapes to trace the movements and foraging behavior of top predators in oceanic ecosystems. In: West JB, Bowen GJ, Dawson TE, Tu KP, editors. Isoscapes. Dordrecht: Springer; 2010. pp. 299-318.

57. Block BA, Teo SL, Walli A, Boustany A, Stokesbury MJ, Farwell $\mathrm{CJ}$, et al. Electronic tagging and population structure of Atlantic bluefin tuna. Nature. 2005;434:1121-7.

58. Wunder MB. Using isoscapes to model probability surfaces for determining geographic origins. In: West JB, Bowen GJ, Dawson TE, Tu KP, editors. Isoscapes. Dordrecht: Springer; 2010. pp. 251270

59. Ramos R, González-Solís J. Trace me if you can: the use of intrinsic biogeochemical markers in marine top predators. Front Ecol Environ. 2012;10(5):258-66. This article highlights the utility of stable isotopes and isoscapes in estimating connectivity among marine predators.

60. McMahon KW, Hamady LL, Thorrold SR. A review of ecogeochemistry approaches to estimating movements of marine animals. Limnol Oceanogr. 2013;58(2):697-714. This review article details emerging trends in the use of stable isotopes to estimate movement of marine animals across seascapes. 
61. Newsome SD, Etnier MA, Gifford-Gonzalez D, Phillips DL, van Tuinen M, Hadly EA, et al. The shifting baseline of northern fur seal ecology in the northeast Pacific Ocean. Proc Natl Acad Sci U S A. 2007;104:9709-14.

62. McCormick M. Variable California spiny lobster foraging across a variable intertidal landscape. Masters thesis, California State University, Monterey Bay. 2016.
63. Iacchei M, Ben-Horin T, Selkoe KA, Bird CE, García-Rodríguez FJ, Toonen RJ. Combined analyses of kinship and FST suggest potential drivers of chaotic genetic patchiness in high gene-flow populations. Mol Ecol. 2013;22(13):3476-94. 